\title{
INFECCCÃO EXPERIMENTAL DE CALOMYS CALLOSUS (RODENTIA CRICETIDAE) COM TRYPANOSOMA CRUZI *
}

Monamaris $M$. Borges **

BORGES, M. M. et al. Infeção experinental de (alomys callosus (Rodentia Cricetidae) com Trypanosoma cruzi. Rev. Saúde públ., S. Paulo, 16:233-42, 1982.

RESUMO: São apresentados resultados sobre a infecção experimental de Calomys callosus (Rodentia) e duas cepas ( $Y$ e Berenice) de Trypanosoma cruzi, isoladas de casos humanos. O estudo da evolução foi feito comparado com Mus musculus albino cepa "Swiss", quanto a prepatência, parasitemia, patência e letalidade. Análise histopatológica foi também conduzida em C. callosus, com o objetivo de verificar o tropismo tissular e agressividade das cepas neste roedor. Os experimentos mostraram que a evolução da infecção em C. Callosus foi diferente para as cluas capas de $\mathbf{T}$. cruzi. A cepa $Y$ apresentou maior parasitemia do que a cepa Berenice. O periodo prepatente variou com as doses utilizadas tendo sido mais curto nos animais inoculados com a cepa $Y(2,2-5,2$ dias $)$ do que naquelas $c o m$ a cepa Berenice $(3,2-7$ dias). Embora as duas cepas inoculadas ros C. callosus tenham-se mostrado miotrópicas, as alteraçôes tissulares foram mais acentuadas com a $Y$. Os resultados obtidos abrem perspectivas quanto à possibilidade do uso de $C$. callosus como animal experimental para $\mathbf{T}$. cruzi.

UNITERMOS: Calomys callosus, Tripanosoma cruzi.

\section{INTRODUCAO}

Alguns trabalhos têm mostrado a facilidade de adaptação do Calomy's callosus (Rodentia Cricetidae) em laboratório (Petter e col.". ${ }^{*}$ 1967; Justines e Johnson ${ }^{13}, 1970$; Mello 1s.19, 1977, 1978).

Trabalhos realizados com $C$. callosus sugerem a possibilidade de que este roedor possa ser um bom modelo experimental de laboratório (Justines e Johnson ${ }^{12}$, 1969; Mello e Teixeira 2:, 1977, Mello e col.2: 1979; Borges e Mello ". 1980; Mello e Borges " ", 1981).
No yue se refere especificamente ao comportamento de $C$. callosus face ao Trypanoroma cruzi existem os trabalhos de Mello e Teixeira 22 (1977), Mello e col.23 (1979), Borges e Mello ${ }^{3}$ (1980) e Mello e Borges 20 (1981). No entanto, todos se referem a estudos experimentais com amostras que foram isoladas de animais silvestres. Assim é que o trabalho aqui apresentado tem por objetivo estudar a evolução da parasitemia e tropismo tissular, produzidos por cepas humanas de $T$. cruzi.

* Trabalho cond zido com auxilio do CNPq (PDE/02-01-06).

** Bolsista do CNPq.

*** Departamento de Medicina Complementar da Faculdade de Ciências da Saúde da Universidaç de Brasilia - Caixa Postal 153031 - $70910 \rightarrow$ Brasilia, DF - Brasil. 
BORGES, M.M. et al. Infeção experimental de Calomys callosus (Rodentia Cricetidae) com Trypanosoma cruzi. Rev. Saúde públ., S. Paulo, 16:233-42, 1982.

\section{MATERIAL E METODOS}

\section{Animais e cepas utilizadas}

Nos experimentos foram utilizadas duas espécies de roedores: $C$. callosus (colônia estabelecida no laboratório e mantida em "inbreding", desde 1975) e Mus musculus albino cepa "Swiss" 40, com idade e pesos variando, respectivamente, entre $30-40$ dias e $21 \mathrm{~g}-23 \mathrm{~g}$.

As cepas de T. cruzi estudadas foram $Y$ (Silva e Nussenzweig ${ }^{29}$, 1953) e Berenice (Salgado e col. ${ }^{28}, 1962$ ), as quais apresentaram no sangue circulante a predominância de formas delgadas (Brener ${ }^{5}, 1965$ ). Os inóculos, consistindo de tripomastigotas sanguícolas, foram os seguintes: 15.000 , $40.000,80.000$ e 120.000 parasitas. A via de inoculação em todos os experimentos foi a intraperitoneal.

Evolução da infeç̧ão: Prepatência, Patência, Parasitemia e Letalidade.

Oito grupos de cinco animais de cada espécie foram inoculados com cada dose acima citada. Com o objetivo de determinar a prepatência da infecção, examinava-se diariamente ao microscópio o sangue da cauda dos animais infectados. Após a prepatência, estes exames passavam a ser realizados alternadamente, três vezes por semana.

A evolução da parasitemia foi acompanhada por um período de 60 dias após as inoculações. As contagens dos parasitas no sangue periférico foram realizadas pelo método de Brener $*$ (1961).

A letalidade foi observada em todos estes grupos experimentais e diariamente eram anotadas, se presente, alterações externas, tais como: eriçamento de pelos, perda de motilidade, diarréia, entre outros.

\section{Parasitismo Tissular}

Com o objetivo de estudar o tropismo tissular e a agressividade das cepas $Y e$ Berenice nos $C$. callosus, foram realizados outros experimentos.
Quatro grupos de oito animais, perfazendo um total de 32 indivíduos, foram inocularlos com as doses já mencionadas. Para observar as variações das lesões em função do tempo, estes animais, em grupos de dois, foram sacrificados nos seguintes dias após as inoculações: $5^{\circ}, 9^{\circ}, 14^{\circ}$ e $21^{\circ}$ dia. Antes de sacrificados, eram realizados exames de sangue para confirmar a infecção.

De cada indivíduo foram retirados fragmentos dos seguintes órgãos: cérebro, pulmão, coração, músculo da perna, rim, baço, esôfago, intestinos delgado e grosso. Estes fragmentos eram fixados em formol a $10 \%$ e incluído em parafina para obtenção dos cortes histológicos (espessura $5 \mu$ ), corados pela hematoxilina-eosina.

\section{RESULTADOS}

\section{Evolução da Infecção: Prepatência, Patência, Parasitemia e Letalidade.}

As Tabelas 1 e 2 mostram os periodos prepatentes para $\mathcal{C}$. callosus e $M$. musculus inoculados com as cepas $Y$ e Berenice. Estes períodos variaram em relação a dose.

Nas Tabelas 3, 4, 5 e 6 estão os dados sobre a evolução da parasitemia nas duas espécies de roedores, inoculados com diferentes doses de $T$. cruzi, e as cepas $\mathrm{Y}$ e Berenice.

Analisando a Tabela 3 , onde estão os resultados da infecção do $C$. callosus com a cepa $Y$, verifica-se que existe uma diferença na evolução da parasitemia entre as duas primeiras doses (15.000 e 40.000) e as duas últimas $(80.000$ e 120.000$)$. Assim é que os picos de parasitemia ocorreram no 80 dia para aqueles animais inoculados com 15.000 e 40.000 tripomastigotas, e no $5^{\circ}$ dia para os inoculados com 80.000 e 120.000 tripomastigotas.

A patência da infecção, no período observado (60 dias), variou de 10-22 dias para os C. callosus inoculados com esta cepa.

A Tabela 4 apresenta a evolução da infecção nos $M$. musculus albinos infectados com a cepa $Y$. Os picos de parasitemia nos $M$. musculus inoculados com a cepa $\mathrm{Y}$ 
BORGES, M.M. et al. Infeção experimental de Calomys callosus (Rodentia Cricetidae) com Trypanosoma cruzi. Rev. Saúde pübl., S. Faulo, 16:233-42, 1982.

ocorreram como segue: animais inoculados com 15.000 no 89 dia após inoculação e $40.000,80.000$ e 120.000 no $7^{\circ}$ dia.

Na Tabela 5 estão os dados sobre a evolução da infecção dos $C$. callosus com a cepa Berenice. Embora os niveis de parasitemia sejam mais baixos do que nos animas inoculados com a cepa $Y$, houve maior regularidade na evolução e a patência mustrou-se mais longa (17-60 dias). Não houve diferenças relevantes quanto ao número de parasitas encontrado no sangue periférico para as quatro doses. No entanto, naqueles animais inoculados com 120.000 tripomastigotas, o pico de parasitemia foi mais alto. Os picos parasitêmicos ocorreram nos seguintes dias após os jnóculos: 12 $(15.000), \quad 9 \%(40.000)$ e $14 \%(80.000$ e 120.000).

T A B E L A 1

Período prepatente em Calomys callosus e Mus Musculus albinos inoculados com diferentes doses de T. cruzi, cepa Y.

\begin{tabular}{|c|c|c|c|c|c|c|c|c|}
\hline \multirow[b]{2}{*}{ Doses } & \multicolumn{8}{|c|}{ Periodo prepatente (dias) } \\
\hline & \multicolumn{4}{|c|}{$\begin{array}{l}\text { C. callosus } \\
\text { Amplitude }\end{array}$} & & \multicolumn{3}{|c|}{$\begin{array}{l}\text { Mus musculus } \\
\text { Amplitude }\end{array}$} \\
\hline 15.000 & $5,2( \pm 0,45)$ & 5 & -. & 6 & 5,0 & - & & - \\
\hline 40.000 & $4,6( \pm 0,55)$ & 4 & - & 5 & $3,2( \pm 0.45)$ & 3 & - & 4 \\
\hline 80.000 & 3.0 & 3 & - & 3 & $3,2( \pm 0,45)$ & 3 & - & 4 \\
\hline 120.000 & $2,2( \pm 0,45)$ & 2 & - & 3 & $2,8( \pm 0,45)$ & 2 & - & 3 \\
\hline
\end{tabular}

$$
\overline{\mathrm{X}}=\text { média }
$$

T A B E L A 2

Periodo prepatente em Calomys callosus e Mus Musculus albinos inoculados com diferentes doses de T. cruzi, cepa Berenice.

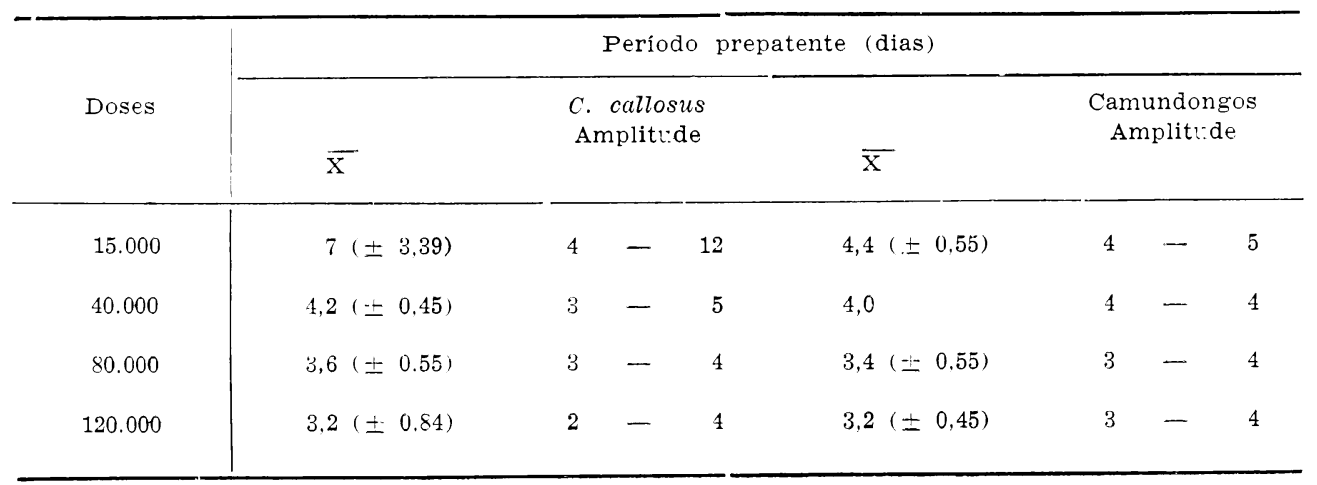

$$
\overrightarrow{\mathrm{x}}^{-}=\text {média }
$$


BORGES, M.M. et al. Infecção experimental ds Calomys callosus (Rodentia Cricetidae) com Trypanosoma cruzi. Rev. Saúde pübl., S. Faulo, 16:233-42, 1982.

\section{T A B E L A 3}

Evolução da parasitemia (no médio de tripomastigotas/5mm 3) em Calomys callosus inoculados com diferentes doses de $T$. cruzi, cepa $\mathrm{Y}$.

\begin{tabular}{|c|c|c|c|c|}
\hline $\begin{array}{l}\text { Ne de } \\
\text { dias após } \\
\text { inoculação }\end{array}$ & 1.5 .000 & 40.000 & 80.000 & 120.000 \\
\hline 2 & - & - & - & 1.200 \\
\hline 3 & - & - & 640 & 17.291 \\
\hline 4 & - & 170 & $\ldots$ & $\ldots$ \\
\hline 5 & 70 & 2.070 & 26.439 & 58.548 \\
\hline 6 & 1.360 & 3.310 & $\ldots$ & $\ldots$ \\
\hline 7 & $\ldots$ & $\ldots$ & 1.780 & 8.693 \\
\hline 8 & 6.750 & 4.950 & $\ldots$ & $\ldots$ \\
\hline 9 & $\ldots$ & $\ldots$ & $\ldots$ & $\ldots$ \\
\hline 10 & 140 & 220 & 220 & 2.800 \\
\hline 12 & $\ldots$ & $\ldots$ & 70 & 1.100 \\
\hline 13 & 70 & 80 & 50 & 12 \\
\hline 15 & 30 & 30 & $\ldots$ & $\ldots$ \\
\hline 17 & - & 40 & - & - \\
\hline 20 & - & 10 & 10 & - \\
\hline 22 & 10 & - & - & - \\
\hline 24 & - & - & - & - \\
\hline
\end{tabular}

T A B E L A 4

Evolução da parasitemia ( ${ }^{\circ}$ médio de tripomastigotas $/ 5 \mathrm{~mm}$ ) em Mus musculus albinos inoculados com diferentes doses de T. cruzi, cepa $\mathrm{Y}$.

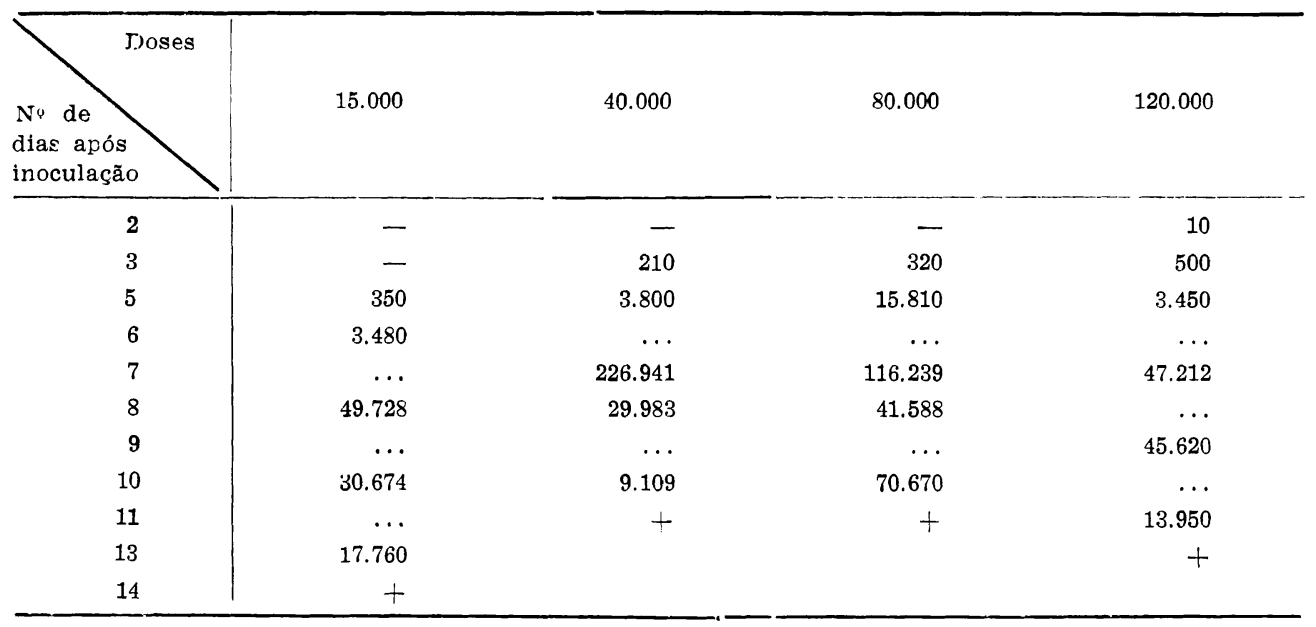

$+=$ Animal encontrado morto. 
BURGES, M.M. et al. Infeç̧ão experimental de Calomys callosus (Rodentia Cricetidae) com Trypanosoma cruzi. Rev, Saíde puibl., S. Paulo, 16:233-42, 1982.

T A B E L A 5

Evolução da parasitemia (n médio de tripomastigotas $/ 5 \mathrm{~mm}$ 3) em Calomys callosus inoculados com diferentes doses de $T$. cruzi, cepa Berenice.

\begin{tabular}{|c|c|c|c|c|}
\hline $\begin{array}{l}\text { Ni de } \\
\text { dias após } \\
\text { inoculação }\end{array}$ & 15.000 & 40.000 & 80.000 & 120.000 \\
\hline 2 & - & - & - & 30 \\
\hline 3 & - & 20 & 30 & 110 \\
\hline 4 & 40 & 230 & 360 & 480 \\
\hline 5 & 100 & 740 & - & - \\
\hline 7 & 230 & 6.660 & 3.310 & 2.310 \\
\hline 9 & 2.410 & 8.625 & 8.664 & 4.520 \\
\hline 12 & 9.850 & 6.930 & 9.770 & 8.600 \\
\hline 14 & 1.873 & 560 & 10.620 & 18.510 \\
\hline 16 & 5.740 & 200 & 8.050 & 6.577 \\
\hline 19 & 4.830 & 200 & 5.350 & 5.194 \\
\hline 21 & 1.550 & 10 & 5.790 & 9.500 \\
\hline 23 & 2.270 & 60 & 3.840 & 5.260 \\
\hline 26 & 290 & 230 & 2.530 & 4.490 \\
\hline 28 & 520 & 100 & 4.500 & 7.520 \\
\hline 30 & 2.070 & 60 & 2.840 & 3.480 \\
\hline 33 & 770 & 70 & 1.500 & 2.190 \\
\hline 35 & 610 & 40 & 1.620 & 2.320 \\
\hline 37 & 1.000 & 30 & 1.090 & 2.370 \\
\hline 40 & 250 & 70 & 430 & 2.640 \\
\hline 42 & 580 & 20 & 880 & 1.900 \\
\hline 44 & 70 & 20 & 410 & 890 \\
\hline 47 & 180 & 0 & 710 & 770 \\
\hline 49 & 350 & 20 & 220 & 490 \\
\hline 51 & 60 & 10 & 210 & 660 \\
\hline 54 & 320 & - & 160 & 440 \\
\hline 56 & 90 & - & 60 & 160 \\
\hline 58 & 110 & - & 90 & 250 \\
\hline 60 & 100 & - & 90 & 140 \\
\hline
\end{tabular}

A Tabela 6 apresenta os resultados quanto à evolução da parasitemia em $M$. musculus infectados com a cepa Berenice. Como se vê, o número de parasitas toi acentuadamente mais alto nos $M$. musculus de que nos $C$. callosus. Os picos de parasitemia ocorreram no 14 o dia para os $M$. musculus inoculados com 80.000 e 120.000 parasitas. Comparando esses dados com aqueles encontrados nos $C$. callosus infectados com a mesma cepa, verificou-se que os picos de parasitemia atingiram periodos mais longos.

Os $C$. callosus não apresentaram sinais de perda de motividade, queda de pêlo ou diarréia tão freqüente nos camundongos inoculados com a cepa $\mathrm{Y}$ e Berenice.

Enquanto a letalidade no período observado, nos $C$. callosus inoculados com as duas cepas foi de $0, \operatorname{nos} M$. musculus foi de $100 \%$. 
BURGES, M.M. et al. Infeç̧ão experimental de Calomys callosus (Rodentia Cricetidae) com Trypanosoma cruzi. Rev. Saúde puibl, S. Paulo, 16:233-42, 1982.

T A B E L A 6

Evolução da parasitemia (no médio de tripomastigotas/5mm 3) em Mus musculus albinos inoculados com diferentes doses de $T$. cruzi, cepa Berenice.

\begin{tabular}{|c|c|c|c|c|}
\hline $\begin{array}{l}\text { Do de } \\
\text { dias após } \\
\text { inoculação }\end{array}$ & 15.000 & 40.000 & 80.000 & 120.000 \\
\hline 2 & - & - & - & - \\
\hline 3 & - & - & 40 & 50 \\
\hline 4 & 30 & 130 & 1.475 & 800 \\
\hline 5 & 80 & 14.720 & 6.960 & 2.390 \\
\hline 7 & 2.280 & 16.934 & 22.200 & 14.444 \\
\hline 9 & 8.994 & 23.902 & 48.455 & 31.938 \\
\hline 12 & 15.614 & 82.288 & 124.764 & 152.255 \\
\hline 14 & 144.300 & 46.126 & 323.380 & 552.780 \\
\hline 16 & 119.986 & 26.233 & + & + \\
\hline 19 & + & 121.360 & & \\
\hline 21 & & + & & \\
\hline
\end{tabular}

$+=$ Animal encontrado morto.

\section{Parasitismo Tissular}

Os resultados sobre os achados teciduais das cepas $\mathrm{Y}$ e Berenice para os $C$. callosus estão nas Tabelas 7 e 8 .

$\mathrm{Na}$ Tabela 7 observa-se que a cepa $Y$ foi tipicamente miotrópica. Foram encontradas lesões nos músculos cardiaco e esquelético, que se caracterizaram por um infiltrado mononuclear focal e/ou difuso e ninhos de amastigotas. Essas lesões foram mais acentuadas no miocárdio. Nos animais inoculados com 40.000 parasitas da cepa $Y$, no $14^{\circ}$ dia após a infecção foi encontrado um quadro característico de miocardite chagásica, com intenso infiltrado inflamatório, hialinização e fibrose, além dos ninhos de amastigotas. Neste grupo o músculo esquelético apresentou apenas infiltrado inflamatório mononuclear e poucos ninhos de amastigotas. Nos grupos inoculados com 80.000 parasitas apenas a presença de fibrose no miocárdio foi observado nos animais sacrificados no $9^{\circ}$ e 21 ㅇ dia após infecção.
Os resultados sobre tropismo tecidual agressividade obtidos com a cepa Berenice estão na Tabela 8. As alterações encontradas com esta cepa foram bem menos acentuadas do que com a cepa Y. Só raros parasitas teciduais no miocárdio foram encontrados. Discretos infiltrados inflamatórios, mononuclear focal ou difuso, no miocárdio e músculo esquelético, foram observados. As alterações foram só ligeiramente mais acentuadas nos animais inoculados com 80.000 parasitas. Houve grupos de animais que não apresentaram alterações.

\section{COMENTARIOS E CONCLUSÕES}

Em experiências de laboratório, $T$, cruzi tem sido estudado em diferentes cepas de camundongos, em ratos, coelhos e cães.

C. callosus roedor da família Cricetidae com ampla distribuição geográfica no Brasil (Mello 17, 1969; Almeida 1, 1973; Mello e Moojen 21, 1979), foi encontrado albergando naturalmente $T$. cruzi por Ribeiro ${ }^{27}$ (1973) e Mello e Teixeira ${ }^{22}$ (1977). 
BORGES, M.M. et al. Infecção experimental de Calomys callosus (Rodentia Cricetidae) com Trypanosoma cruzi. Rev. Saúde puibl., S. Paulo, 16:233-42, 1982.

\section{T A B E L A 7}

Tropismo tecidual em Calomys callosus inoculados com diferentes doses de $T$. cruzi, cepa Y.

\begin{tabular}{|c|c|c|c|c|c|c|c|c|}
\hline \multirow{3}{*}{ Doses } & \multicolumn{4}{|c|}{$\begin{array}{l}\text { Tecidos lesados } \\
\text { e parasitados }\end{array}$} & \multicolumn{4}{|c|}{$\begin{array}{l}\text { Tecidos lesados } \\
\text { sem pasasitos }\end{array}$} \\
\hline & \multicolumn{8}{|c|}{ Dias após inoculação } \\
\hline & $5^{\circ}$ & $9 \circ$ & $14^{\circ}$ & $21^{\circ}$ & $5^{\circ}$ & $99^{\circ}$ & $14^{\circ}$ & $211^{\circ}$ \\
\hline 15.000 & - & $\mathrm{mi}$ & me & - & - & - & mi-me & $\mathrm{me}$ \\
\hline 40.000 & - & mi-me & mi-me & - & - & - & - & $\mathrm{mi}$ \\
\hline 80.000 & $\mathrm{mi}$ & $\mathrm{mi}$ & - & - & - & - & $\mathrm{mi}$ & $\mathrm{mi}$ \\
\hline 120.000 & - & mi-me & me & - & $\mathrm{mi}$ & mi-me & $\mathrm{mi}$ & mi-me \\
\hline
\end{tabular}

$\mathrm{Mi}=$ Miocardio.

$\mathrm{Me}=$ Músculo esquelético.

T A B E L A 8

Tropismo tecidual em Calomys callosus inoculados com diferentes doses de $T$. cruzi, cepa Berenice.

\begin{tabular}{|c|c|c|c|c|c|c|c|c|}
\hline \multirow{3}{*}{ Doses } & \multicolumn{4}{|c|}{$\begin{array}{l}\text { Tecidos lesados } \\
\text { e parasitados }\end{array}$} & \multicolumn{4}{|c|}{$\begin{array}{l}\text { Tecidos lesados } \\
\text { sem parasitados }\end{array}$} \\
\hline & \multicolumn{8}{|c|}{ Dias após inoculação } \\
\hline & $5^{\circ}$ & 98 & $14{ }^{\circ}$ & $21^{\circ}$ & $5 ?$ & 9 9 & $14^{\circ}$ & $21^{\circ}$ \\
\hline 15.000 & - & 一 & $\mathrm{mi}$ & - & - & - & - & mi-me \\
\hline 40.000 & - & - & - & - & - & - & $\mathrm{mi}$ & $\mathrm{mi}$ \\
\hline 80.000 & - & - & - & $\mathrm{mi}$ & - & $\mathrm{mi}$ & $\mathrm{mi}$ & - \\
\hline 120.000 & - & - & - & - & - & - & $\mathrm{mi}$ & $\mathrm{mi}$ \\
\hline
\end{tabular}

$\mathrm{Mi}=$ Miocardio.

$\mathrm{Me}=$ Músculo esquelético.

Estudos sobre infecção experimental em $C$. callosus com cepas silvestres de $T$. cruzi foram realizados por Mello e Teixeira ${ }^{22}$ (1977), Mello e col.23 (1979), Borges e Mello ${ }^{3}$ (1980) e Mello e Borges 20 (1981). Os resultados obtidos por estes autores mostraram peculiaridades na interação parasito-hospedeiro. Assim é que estes animais inoculados com cepas de $T$. cruzi silvestres apresentaram parasitemias regulares médias, superiores a camundongos albinos subme- tidos aos mesmos experimentos. A letalidade destas cepas em $C$. callosus foi $7 \%$ e em camundongos $12 \%$. O parasitismo tissular assim como as lesões encontradas foram mais evidentes em camundongos de que nos $C$. callosus. As cepas estudadas pelos referidos autores foram miotrópicas para as duas espécies de roedores.

No trabalho aqui apresentado, $C$. callosus foi estudado quanto à infecção a duas cepas 
BORGES, M.M. et al. Infecção experimental de Calomys callosus (Rodentia Cricetidue) com Trypanosoma cruzi. Rev. Saúde públ., S. Faulo. 16:233-42, 1982.

de $T$. cruzi, Y e Berenice, isoladas de casos humanos. Estudos experimentais com estas cepas foram conduzidos por vários autores (Silva e Nussenzweig 28, 1953; Phillips ${ }^{24}$, 1960; Leme e Collares ${ }^{16}$, 1962; Brener ", 1965; Carvalheiro e Collares ${ }^{8}$, 1965; Andrade 2, 1974; Chiari 9, 1977; Mello e Brener ${ }^{24}, 1978$; Sogayar ${ }^{1 "}$, 1978; Corsini e col.1", 1980). Os animais utilizados nessas pesquisas foram principalmente camundongos e ratos albinos. Essas duas cepas são altamente virulentas, apresentam padrão de evolução de parasitemia semelhantes, caracterizando-se por picos entre 7 : e 80 dia. Variações podem ser encontradas em relação a dose inoculada. No entanto, a letalidade é sempre alta e ambas produzem intensas lesões no sistema reticulo endotelial. As prepatências das cepas $\mathrm{Y}$ e Berenice estão em torno de 3-4 dias, respectivamente.

Nos experimentos realizados verificou-se (Tabelas 3 e 5) que as cepas $Y$ e Berenice quando inoculadas em $C$. callosus apresentaram diferentes resultados. A cepa $\mathrm{Y}$ mostrou parasitemia mais alta do que a Berenice, embora tenha ocorrido variaçóes em relação a dose. Os picos de parasitas no sangue circulante ocorreram com a cepa $Y$ entre $5^{\circ}$ e $8^{\circ}$ dia após inoculação e com a cepa Berenice entre 9" e $14^{\circ}$ dia.

Nas condiçōes padronizadas neste trabalho, o periodo prepatente da cepa $\mathrm{Y}$ foi menor do que a Berenice (Tabela 1). O mesmo foi observado em relação a patência que variou de 13-22 dias com a $Y$ e 17-60 dias com a Berenice. As alterações tissulares foram mais intensas nos animais inocuiados com a cepa Y. Nestes, foi frcqüente o encontro de pseudocistos e infiltrados inflamatórios, além do quadro de miocardite chagásica. As duas cepas foram miotrópicas.

As cepas Y e Berenice têm sido consideradas como sendo reticulotrópicas quando inoculadas em camundongos (Brener ${ }^{5}$, 1665; AnGrade 2, 1974 e Mello e Brener ${ }^{24}$, 1978). Em experimentos realizados com ratos albinos, Leme e Collares 1ti (1962) e Sogayar 30 (1978), observaram que essas cepas foram miotrópicas. Como foi discutido acima, nos experimentos realizados com Calomys callosus, essas mesmas cepas apresentaram tropismo exclusivamente muscular. Verifica-se, portanto, que o tropismo celular é independente da cepa do $T$. cruzi utilizada. Isso indica que provavelmente esse fenômeno está relacionado a tipos de respostas imunológicas diferentes ao parasito, dadas por hospedeiros específicos. Sem dúvida, numerosos complexos e ainda desconhecidos fatores, estão envolvidos na defesa dos hospedeiros vertebrados ao $T$. cruzi. O papel da imunidade humoral e celular em relação ao $T$. cruzi, principalmente em experimentos realizados com camundongos, tem sido estudado por vários autores (Kierszenbaun e Howard 1t, 1976; Krettli e Brener 15, 1976; Hanson 11, 1977; Castelo Branco : 1978 e Brener ${ }^{6}, 1980$ ).

Os resultados obtidos no presente trabalho mostraram ser o $C$. callosus um animal que pode se prestar à estudos imunológicos quando infectados com $T$. cruzi. Este roedor é um animal pouco estudado. Nele pode ser encontrado uma rica fonte de assuntos a serem pesquisados. Ressalta-se o fato de que sua manutenção no laboratório foi conseguida com facilidade e que é una espécie que apresenta um bom indice de reprodução (Mello 18.19, 1977 e 1978). 
BORGES, M.M. et al. Infeç̧ão experimental de Calomys callosus (Fiodentia Cricetidae) com Trypanosoma cruzi. Rer. Saúde púbt., S. Püulo, 16.233-42. 1982.

EORGES. M. M. et al. [Results of the experimental iufection of Calomys callosus (Rodentia) with human strains of Trypanosoma cruzil. Rer. Saúde públ., S. Paulo, 16:283-42, 1982 .

ABSTRACT: An albino "swiss" strain of Mus musculus was used for comparison purposes with regard to the following parameters: parasitemia, prepatent period, patency of the infection and lethality. Histopathological studies were carried out with the aim of observing the tiscue tropism and aggressiveness of $\mathbf{T}$. cruzi against $\mathbf{C}$. callosus. The experiments showed that the evolution of the infection in C. callosus was different according to the two $\mathbf{T}$. cruzi strains utilized. They strain produced higher parasitemia than the Berenice strain. The prepatent period varied as a result of the inocuia being shorter in the animals inoculated with the strain $Y(2,2-3,2$ days $)$ than in those infected with the Berenice strain (3, 2-7, 0 days). Although both strains were shown to be myotropic, the tissue alterations were more pronounced in the animals inoculated with the $Y$ strain. Results indicated the possibility that $C$. callosus may be used as experimental animals for 'I'. cruzi infection.

CNITERMs: Calomys callosus. Trypanosoma cruzi.

\section{REFERENCIAS BJBLIOGRÁFICAS}

1. ALMEIDA. C.R. Relatório das pesquisas do Plano Piloto de Peste em Exu. Recife. Centro de Pesquisas Aggeu Magalhães/ Ministério da Saúde. 1973. [mineografado]

2. ANDRADE, S. Caracterização de cepas de $T$. cruzi isoladas no Recôncavo Baiano. Rev. Patol. trop. 1:65-121, 1974.

3. BORGES, M.M. \& MELLO, D.A. Infectividade de cepas silvestres de Trypanosoma cruzi mantidas em cultura, para Calomys callosus (Rodentia) e camundongos albinos. Rex. Patol. trop., 9:145$-51,1980$.

4. BRENER, Z. Contribuição ao estudo da terapêutica experimental da Doença de Chagas. Belo Horizonte, 1961. [Tese de Livre Docencia - Faculdade de Odontologia e Farmácia da UFMG]

5. BRENER, Z. Comparative studies of ditferent strains of Trypanosoma crazi. Ann. trop. Med. Parasit., 59:19-26, 1965.

6. BRENER, Z. Immunity to Trypanosoma cruzi. Adr, Parasit., 18:247-92, 1980.

7. CASTElo BRANCO. A.Z.C.L. Proteção mediada por imunoglob:lina G em camontongos infectados com Trypanosoma cruzi. Belo Horizonte. 1978. [D1ssertação de Mestrado - Instituto de Ciências Biomédicas ta UFMGJ

8. Carvalheiro, J. da R. \& COLlares. E.F. Estudos sobre o comportamento em camundongos de uma amostra altamente virulenta de Trypanosoma critai (Amostra $\mathrm{Y}$. após passagem em triatomíneos, ratos e culturas. Rer. bras. Biol. 25: $169-75, \quad 1965$.

9. CHIARI, C.A. Comportamento de diferentes amostras de Trypanosoma cruzl em cobaias experimentalmente infectadas. In: Reuniāo Anual de Pesquisa Básica em Doença de Chagas, 4\%, Caxambu 1977. Resumos. Caxambu. 1977. p. 23.

10. CORSini, A.C.: COSTA, M.G.: OLIVEIRA. O.L.P.: CAMARGO, I.J.B. \& STELINI Jr., A. Susceptibility of inbred mice to Trypanosoma cruzi strain Y. Rer. Jnst. $M=d$. trop. S. Paulo, 2: $: 192-6,1980$.

11. HANSON, W.L. Immune response and mechanisms of resistence in T:ypanosoma cruzi. In: Chagas' disease: proceedings. Washington, D.C., Pan American Health Organization. 1977. p. 22-34. (PAHO-Scient. publ. 347). 
BORGES, M.M. et al. Infeç̧ão experimental de Calomys callosus (Rodentia Cricetidae) com Trypanosoma cruzi. Rev. Saúde públ., S. Paulo, 16:233-42, 1982.

12. JUSTINES, G. \& JOHNSON, K.M. Immune tolerance in Calomys callosus infected with Machupo virus. Nature, 222:1090-1, 1969.

13. JUSTINES, G. \& JOHNSON, K.M. Observations on the laboratory breeding of the Cricetidae rodent Calomys callosus. Lab. Anim. Care, 20:57-60, 1970.

14. KIERSZENBAUN, F. \& HOWARD, J.G. Mechanisms of resistance against experimental Trypanosoma cruzi infection: the importance of antibodies and antibodyforming capacity in the Biozzi high and low responder mice. $J$. Immunol., $112: 1839-44,1976$.

15. KRETTLI, A.U. \& BRENER, Z. Protective effects of specific antibodies in Trypanosoma cruzi infection. J. Immunol., 116:755-60, 1976.

16. LEME, M.V.S. \& COLLARES, E.F. Estudos sobre a suscetibilidade de ratos brancos a uma amostra de Trypanosoma cruzi altamente virulenta para camundongo (Amostra Y). Medicina, Ribeirão Preto, $1: 109-11,1962$.

17. MELLO, D.A. Roedores silvestres de alguns municípios do Estado de Pernambrico e suas regioes naturais. Rev. bras. Pesq. med. biol., 2:360-2, 1969.

18. MELLO, D.A. Note on breeding of Calomys expulsus, Lund, 1841 (Rodentia, Cricetidae) under laboratory conditions. Rev. bras. Pesq. med. biol., 10:107, 1977.

19. MELLO, D.A. Biology of Calomys callosus (Rengger, 1830) under laboratory conditions (Rodentia, Cricetidae). Rev. bras. biol., $38: 807-11,1978$.

20. MELlo. D.A. \& BORGES, M.M. Primeiro encontro do Triatoma costalimai naturalmente infectado pelo Trypanosoma cruzi: estudo de aspectos biológicos da amostra isolada. Mem. Inst. Oswaldo Cruz, $76: 61-9,1981$.

21. MELLO, D.A. \& MOOJEN, L. Nota sobre uma coleção de roedores e marsupiais de algumas regiões do cerrado do Brasil Central. Rev. bras, Pesq. méd. biol. $12: 267-91,1979$.
22. MELLO, D.A. \& TEIXEIRA, M.L. Nota sobre infecção natural do Calomys expulsus, Lund 1841 (Rodentia, Cricetidae) pelo Trypanosoma cruzi. Rev. Saúde puibl., S. Paulo, 11:561-4, 1977.

23. MELLO, D.A.; VALIN, E. \& TEIXEIRA, M.L. Alguns aspectos do comportamento de cepas silvestres de Trypanosoma cruzi em camundongos e Calomys callosus (Rodentia). Rev, Saude públ., S. Paulo, $13: 314,25,1979$.

24. MELLO, R.C. \& BRENER, Z. Tissue tropism of different Trypanosoma cruzi strain. J. Parasit., 64:475-82, 1978.

25. PETTER, F.; KARIMI, Y. \& ALMEIDA, C.R. Un nouveau rongeur de laboratoire, le Cricetidé Calomys callosus. C.R. Acad. Sci. Paris, 265:1974-6, 1967.

26. PHILliPS, N.R. Experimental studies in the quantitative transmission of Trypanosoma cruzi: considerations regarding the standardization of materials. Ann. trop. Med. Parasit., 54:60-70, 1960.

27. RIBEIRO, R.D. Novos reservatórios do Trypanosoma cruzi. Rev. bras. Biol. $33: 429-537,1973$.

28. SALGADO, L.A.; GARCEZ, P.N.; OLIVEIRA, C.A. \& GALLIZZI, L. Revisão clínica atual do primeiro caso humano descrito da doença de Chagas. Rev. Inst. Med. trop. S. Paulo, 4:330-7, 1962.

29. SILVA, L.H.P. da \& NUSSENZWEIG, V. Sobre a cepa de Trypanosoma cruzi altamente virulenta para camindongo branco Folic clin. biol., 20:191-207, 1953.

30. SOGAYAR, R. Infecção experimental de ratos albinos wistar com diferentes cepas de Trypanosoma cruzi, Chagas 1909. Belo Horizonte, 1978. [Dissertação de Mestrado - Instituto de Ciências Biomédicas da UFMG]

Recebido para publicação em 07/01/1982 A provado para publicacão em 11/05/1982 